\title{
DYNAMIC ANALYSIS AND OPTIMIZATION OF PROCESS PARAMETERS IN TURNING OPERATION BY USING ADAMS SOFTWARE
}

\author{
Subhash Chandra Namdeo \\ Research Scholar, M. Tech. in Production Engineering, \\ Department of Mechanical Engineering, \\ Dr. C.V. Raman Institute of Science and Technology, \\ Kargi Road - Kota, Bilaspur, India
}

\begin{abstract}
Metal turning process is a widely used process in Metal removal operations for reducing the diameter of workpiece. The force obtained in these operations are investigated experimentally and analytically with the help of numerical and optimization methods. Since, these machining operations have a complex structure; it is quite difficult to solve them analytically. Experimental method is also both costly and time consuming. However, this complex structure can be solved and analyze easily by using CAD based dynamic analysis software like ADAMs. This paper consist a software approach for dynamic analysis and optimization of process parameter in turning operation. The process of turning is influenced by many parameters such as cutting speed, feed rate and depth of cut; which are difficult to analyze analytically and experimentally; can be easily identified by using simulation tools on ADAMs. This Paper work contains a three dimensional dynamic modeling of turning process and simulation of model, to identify the effect of process parameter on various forces like Cutting force, Feed Force and Radial force and also to optimize the parameters for minimum cutting force. The magnitude of force variation thus obtained is further validated with the experimental results. The dynamic force magnitudes obtained experimentally and obtained in ADAMs are closely matching. This proves that the accuracy of the developed 3D model, dynamic analysis software and analytical model.
\end{abstract}

Index Terms: Turning Process, Modeling, Dynamic Analysis, Cutting Force, Feed Force, Optimization, ADAMs Software 
Cite this Article: Subhash Chandra Namdeo, Dynamic Analysis and Optimization of Process Parameters In Turning Operation by Using Adams Software. International Journal of Design and Manufacturing Technology 7(2), 2016, pp. 14-31.

https://iaeme.com/Home/issue/IJDMT?Volume $=7 \&$ Issue $=2$

\section{INTRODUCTION}

Turning is the removal of metal from the external diameter of a cylindrical work piece. Turning is used to reduce the external diameter of the work piece, usually to a given dimension. Often the work piece will be turned so that adjacent sections have different diameters, called as stepped turning operation. In its basic form, Turning can be defined as the machining operation that produces cylindrical objects, with the work piece rotating, with a single-point cutting tool and with the tool feeding parallel to the axis of the work piece at a distance that will remove the external surface of the work. Taper turning is also same, except that the cutter path is at an angle to the work axis. Similarly, in contour turning, the distance of the single point tool from the axis of workpiece is varied to generate the desired shape. The single-point tool operates independently as a single-point cutter. The classes of cutting tool materials currently in use for metal removal operation are high-speed tool steel (HSS.), cobalt-base alloys, cemented carbides, ceramic and cubic boron nitride $(\mathrm{CBN})$ and diamond. Different machining applications require different cutting tool materials. The Ideal tool material should have the following characteristics (1) Harder than the work it is cutting (2) High temperature stability (3) Resists wear and thermal shock (4) Impact resistant (5) Chemically inert to the work material and cutting fluid. The turning machines are, of course, every kind of lathes. Lathes used in manufacturing can be classified as engine, turret, automatics and CNCs. Many engine lathes are equipped with chip pans and built-in coolant circulating system. In a turret lathe, a longitudinally feed able, hexagon turret replaces the tailstock. The turret, on which six tools can be fixed, can be rotated about a vertical axis to bring each tool into working position, and the entire tool post can be moved longitudinally, either annually or by power, to provide feed for the tools.

Recently, performing metal turning processes based on the dynamic analysis method in a computer environment is very significant in terms of both lowering the higher costs brought by experimental method and time efficiency. Considering the metal cutting processes analytically, they are very complex problems to solve. In such cases, Dynamic analysis in a computer environment provides a good alternative solution. However, correct load and boundary conditions should be applying in order to get better results from the method. Otherwise, if undesirable results may occur; the friction coefficient between the components and material models must be entered correctly.

\section{LITERATURE SURVEY}

Many studies have been made using Taguchi and grey relational Method to optimize the turning parameter.

W.H Yang and Y.S Tang (1997) [1], carried out an experiment consist of eighteen combination on an engine lathe using tungsten carbide for the machining of S45C steel bars. The cutting parameters that have been selected are cutting speed, feed rate and depth of cut with the respond variable, tool life and surface roughness. Result show that cutting speed and feed rate are the essential cutting parameters for affecting 
tool life, while the change of the depth of cut has an inconsiderable effect on tool life. For surface roughness, all the cutting parameters have the significant effect. The correction of tool life and surface roughness from selected initial parameters to the optimal cutting parameters is about $250 \%$.

G.M. Sayeed Ahmeda, S. Sibghatullah Hussaini Quadri, Md Sadiq Mohiuddin (2015) [2], they conducted an experiment on lathe turning machine with mild steel as work material and High Speed Steel as a tool material and optimize the turning parameters such as cutting force and feed force by using Taguchi design approach. They use L9 orthogonal array with nine total experiments, to study the performance characteristics in turning operations of mild steel bars by using high speed steel cutting tools. In this research work, three cutting parameters namely, cutting speed, feed rate, and depth of cut, are optimized minimum cutting force and feed force. The experimental results state that the cutting speed and feed rate are the main parameters among the three controllable parameters (cutting speed, feed rate and depth of cut) that influence the cutting and feed forces in turning of mild steel.

Atul B. Andhare and Manish Kumar Verma (2015) [3], developed a virtual model of an ideal gear pair in Adams and variation of the dynamic force is obtained by comprehension the tooth mesh stiffness and mesh damping coefficient. In this research work, Automatic Dynamic Analysis of Mechanical Systems (ADAMS) software is used for modeling and simulation of spur gear pair mechanism. The magnitude of force variation thus obtained is validated with the design calculations and the result of this research says; the dynamic force magnitudes obtained and found in Adams are closely matching.

Kamble and Saha (2007) [4], developed virtual prototype model of rack and pinion gear steering system with incorporated manufacturing error. They used ADAMS software for simulation. In this research work, a prototype developed in Automatic Dynamic Analysis of Mechanical Systems (ADAMS) software, where, the steering system errors are also incorporated. After the simulation of prototype is done, Comparisons of the results from the virtual prototype simulation with those from laboratory experiments validate the correctness of the proposed prototype in ADAMS.

Kadir Gok (2015) [5], they conducted a three-dimensional finite element model to calculate the processing parameters in turning operation. In this study, a 3D FEM model and analysis software (ANSYS) were used for turning processes. In this study, an analytic model and software was developed for calculating mechanical energy, the heat transfer coefficients, and the friction coefficients at the tool-chip. A comparison was performed for temperature, cutting force and thrust force obtained from experiment and numerical analyses. It can be said that the 3D FEM model provides reasonable results with experimental results in view of temperature, cutting force, and thrust force. It can be said that the 3D Finite Element model gives closer results with experimental results in view of temperature, cutting force and thrust force. This proves that the accuracy of the developed 3D finite element model, software and analytical model.

From this literature survey, it was found that there is lots of work has done on optimization of turning operation for minimum cutting force and surface roughness by analytical and experimental method. But there is insufficient work to describe the dynamic analysis and optimization for various machining operations like turning. Also, from the literature we see that the ADAMS is a powerful type for simulation software to analyze the machining operations like turning or others. Therefore, it was planned to simulate the turning mechanism under different process parameters like 
cutting speed, feed rate and depth of cut to find the cutting and feed forces by using ADAMS. This paper describes the dynamic analysis of turning operation under variable parameters by using ADAMS - View.

\section{MATERIAL INVESTIGATION}

\subsection{Workpiece Material}

In turning, the raw material is a workpiece of stock from which the work pieces are cut. This stock is available in various shapes such as solid cylindrical bars and hollow cylindrical tubes. Turning can be performed on a variety of materials like; aluminum, brass, magnesium, nickel, steel, thermoplastics, titanium and zinc. Low-carbon steel contains approximately $0.05-0.6 \%$ carbon and mild steel contains $0.05-0.3 \%$ carbon; making it malleable and ductile. Mild steel has relatively low yield strength, but it is cheap, tough and malleable; surface hardness can be increased through carburizing surface hardening process. It is often used when large amount of steel are needed, for example as structural steel. The Material Composition and Material Properties for mild steel are taken as follows:-

Table 3.1 Composition of Mild Steel

\begin{tabular}{|c|c|c|c|c|c|}
\hline Elements & Carbon & Manganese & Phosphorous & Sulphur & Iron \\
\hline $\begin{array}{c}\text { For } \\
\text { Mild Steel }\end{array}$ & $0.15 \%$ & $0.85 \%$ & $0.90 \%$ & $0.35 \%$ & $97.91 \%$ \\
\hline
\end{tabular}

Table 3.2 Properties of Mild Steel

\begin{tabular}{|c|c|c|c|c|c|}
\hline Properties & Hardness & $\begin{array}{c}\text { Yield } \\
\text { Strength }\end{array}$ & Density & $\begin{array}{c}\text { Young's } \\
\text { Modulus }\end{array}$ & $\begin{array}{c}\text { Poisson' } \\
\text { s ratio }\end{array}$ \\
\hline $\begin{array}{c}\text { For } \\
\text { Mild Steel }\end{array}$ & $170 \mathrm{BHN}$ & $200 \mathrm{MPa}$ & $7850 \mathrm{Kg} / \mathrm{m}^{3}$ & $210 \mathrm{GPa}$ & 0.303 \\
\hline
\end{tabular}

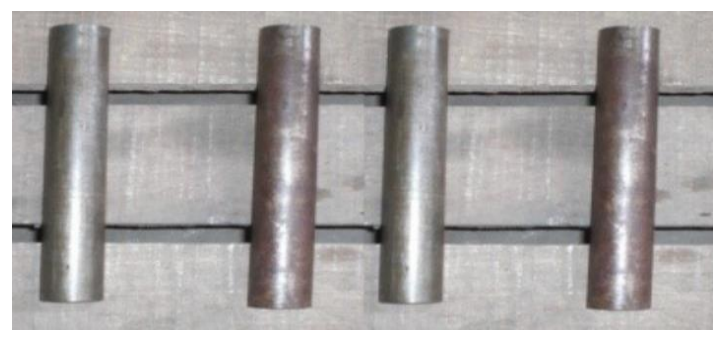

Figure 3.1 Turning Materials (Mild Steel Workpiece)

\subsection{Cutting tool material}

The main objective of cutting tool material is to remove the material under controlled conditions. Therefore the tool must be harder than the material which it is to cut, i.e. cutting material should be denser as compare to the workpiece material. The cutting tools are made up of different materials such as; carbon tool steels, high speed steels, cemented carbides, ceramics and diamonds etc. the cutting tool material should possess the following properties:-

- It should be strong enough to withstand the forces being applied due the cutting i.e. bending, compression, shear etc. 
- It should be tough enough to resist the shock loads,

- It should be sufficient harder to resist wear, abrasion and indentation.

- It should be able to resist the high temperature.

- The coefficient of friction between the chip and the tool should be as low as possible in the operating range of speed and feed.

A high speed steel tool gives improved cutting performance and higher metal removal rates. High speed steel is widely used for single point cutting tools, drill bits and milling cutters etc. Although many types of high speed steel are in use but T83Mo6W6Cr4V2 designation of high speed steel material is quite commonly used for single point cutting tools. This type of material gives excellent performance over a great range of materials and cutting speeds and it retains its hardness up to $600^{\circ} \mathrm{c}$. the composition and properties of high speed steel tool used for machining are as follows

Table 3.3 Composition of High Speed Steel

\begin{tabular}{|l|l|}
\hline \multicolumn{1}{|c|}{ Elements } & \multicolumn{1}{c|}{ Wt.\% } \\
\hline Carbon & $1.20 \%-1.40 \%$ \\
\hline Manganese & $0.50 \%$ \\
\hline Silicon & $1.00 \%$ \\
\hline Chromium & $3.50 \%-4.50 \%$ \\
\hline Vanadium & $2.25 \%-2.75 \%$ \\
\hline Tungsten & $5.60 \%-6.40 \%$ \\
\hline Molybdenum & $5.60 \%-6.40 \%$ \\
\hline Cobalt & $5.00 \%-7.00 \%$ \\
\hline
\end{tabular}

Table 3.4 Properties of High Speed Steel

\begin{tabular}{|l|l|}
\hline \multicolumn{1}{|c|}{ Properties } & \multicolumn{1}{c|}{ Values } \\
\hline Poisson's Ratio & 0.28 \\
\hline Young's Modulus & $2.07 \mathrm{e}+05 \mathrm{MPa}$ \\
\hline Co-effi. of thermal expansion & $1.18 \mathrm{e}-05 /{ }^{\circ} \mathrm{c}$ \\
\hline Ultimate Compressive Stress & $3300 \mathrm{MPa}$ \\
\hline Thermal Conductivity & $22 \mathrm{~N} / \mathrm{sec} . \mathrm{K}$ \\
\hline Density & $8138.00 \mathrm{Kg} / \mathrm{m}^{3}$ \\
\hline
\end{tabular}

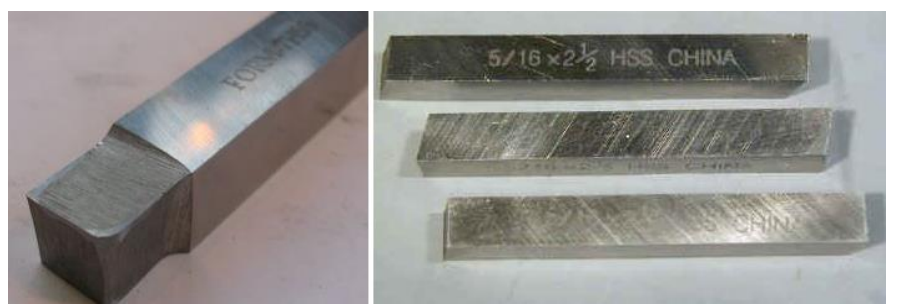

Figure 3.2 High Speed Steel Cutting tools 


\section{EXPERIMENTAL PROCEDURES}

\subsection{Process Parameters}

In turning, the cutting speed and feed motion of the cutting tool is specified through various parameters. These parameters are specified for each operation based upon the work piece material, tool material and tool size etc. Turning parameter that can affect the process is:

1. Cutting speed $(\mathbf{V})$ - The speed of the work piece surface with relative to the edge of the cutting tool during a cut, measured in meters per minute (MPM). For Example; In the turning operation when a workpiece of diameter D rotates at a speed of $\mathrm{N} \mathrm{rpm}$ the cutting speed (V) is given by;

$V=\frac{\pi D N}{1000} \mathrm{~m} / \mathrm{min}$

Where, $\mathrm{D}=$ Dia. Of workpiece (in $\mathrm{mm}$ )

$\mathrm{N}=$ Spindle Speed (in rpm)

- The cutting speed for turning of mild steel workpiece with HSS cutting tool varies $10 \mathrm{~m} / \mathrm{min}$ to $50 \mathrm{~m} / \mathrm{min}$.

2. Spindle speed $(\mathbf{N})$ - It is the rotational speed of the spindle and the work piece, measured in revolutions per minute.

The spindle speed is equal to the cutting speed of workpiece divided by the circumference length of the work piece where the cut is being made. In order to preserve a constant cutting speed, the spindle speed should vary based on the diameter of the cut, with the help of gear box. If the spindle speed is held constant, then the cutting speed will vary.

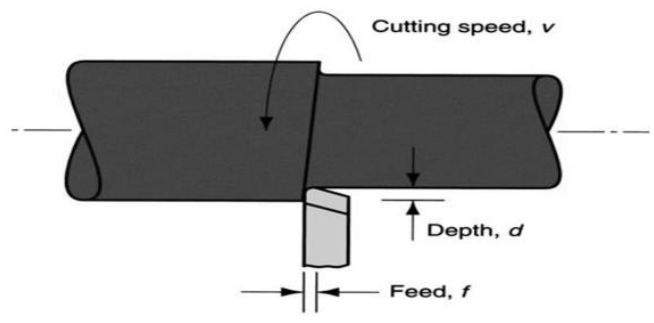

Figure 4.1 Turning Operation

3. Feed rate (f) - It is the speed of movement of the cutting tool relative to the work piece as the tool makes a cut. The feed rate is measured in millimeter per revolution (MPR).

- The feed rate for turning of mild steel workpiece with HSS cutting tool varies $0.1 \mathrm{~mm} / \mathrm{rev}$ to $1 \mathrm{~mm} / \mathrm{rev}$.

4. Depth of cut - It is the thickness of material removed from the work material in the radial direction, measured in mm per pass.

\subsection{Experimental Setup}

A conventional engine lathe machine has been used for the experiment having different parameters. Different range of cutting speed can be chosen in engine lathe machine by shifting the gears according to required speed. Piezo-electric threecomponent dynamometer has been used for measuring the feed force, cutting force 
and radial force Readings from the dynamometer. These readings are measured in $\mathrm{x}, \mathrm{y}$ and $\mathrm{z}$ directions respectively. Readings were fed to the computer for analytical and saving purposes.

The Experiment has been conducted by Turning of mild steel, using HSS single point cutting Tool. The cutting force components in $\mathrm{x}, \mathrm{y}$ and $\mathrm{z}$ directions has been measured with a Piezo-electric three-component dynamometer with the help of a multi channel charge amplifier and a data acquisition system. Experiments were carried out under various cutting conditions like different cutting speeds, feed rates and depth of cut. During the turning operation the following various forces are occurs on the tool:-

- Feed force $(\mathrm{Ft})$ :- It is the force which acts parallel to the axis of work piece and is in the reverse direction of the feed. The dynamometer indicates the cutting force in the downward $\mathrm{x}$-direction.

- Cutting force $\left(F_{c}\right)$ :- It acts against the workpiece turning motion on the cutting tool and downwards perpendicular to the workspace axis. The dynamometer indicates the cutting force in the downward y-direction.

- Radial force $\left(F_{r}\right)$ :- It is the force that tends to push the tool away from the workpiece and forces the cutting tool backwards. It acts perpendicular to the generated surface and also known as thrust force.

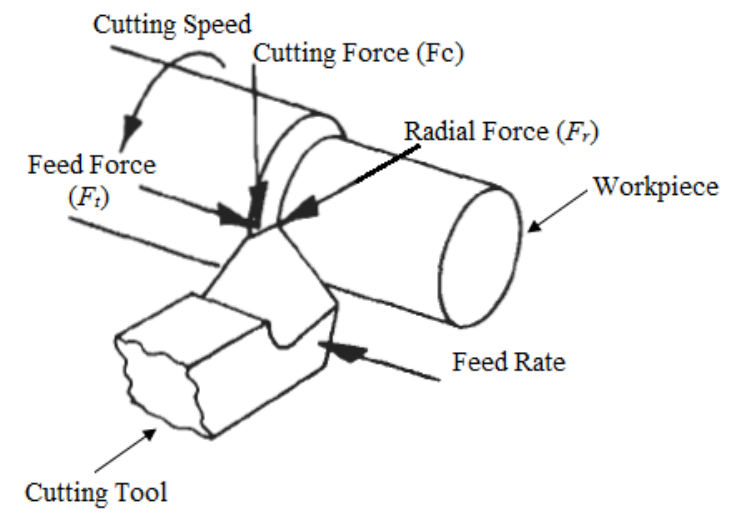

Figure 4.2 Force Mechanism for Turning Operation
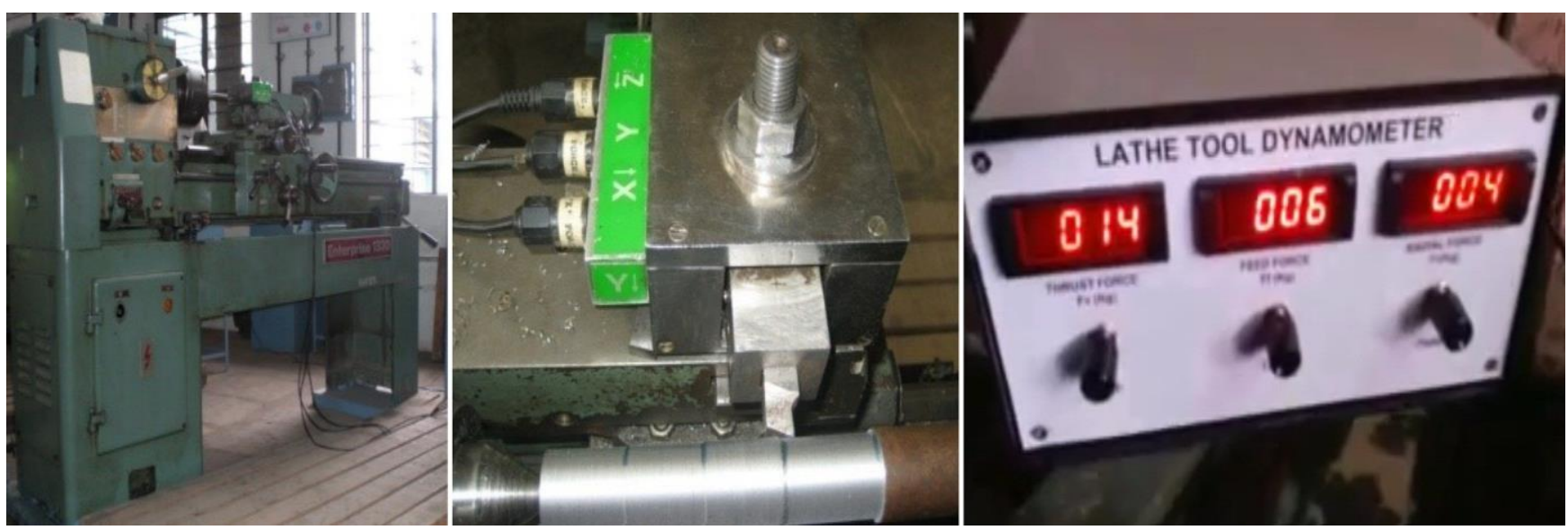

Figure 4.3 Dynamometer setup for lathe machine and Dynamometer display readings 
Dynamic Analysis and Optimization of Process Parameters in Turning Operation by Using ADAMS Software

\subsection{Design of experiment}

\subsubsection{METHODOLOGY}

Design of Experiments consist a procedure for optimization of process parameters to obtain BEST results which is achieved in the Taguchi Method. "Orthogonal Arrays" (OA) gives a set of minimum experiments and Taguchi's Signal-to-Noise ratios (S/N), which are $\log$ functions of desired output. The Signal-to-Noise ratio (S/N Ratio) serves as objective functions for optimization of parameters and help in data analysis and prediction of optimum results. The Taguchi method is best used when there are number of variables present from 3 to 50. The L9 (3*3) Array in Taguchi's method represents; 3 LEVELS and 3 PARAMETERS which makes a NINE set of experiments as shown in table 4.1 and table 4.2. A main effect is present when different levels of parameters affect the response variables differently. The results obtain has been analyzed by using MINITAB software. The MINITAB software is used to find the $\mathrm{S} / \mathrm{N}$ ratios and to plot the graph for $\mathrm{S} / \mathrm{N}$ ratio with respect to process parameters for specific response variables. When the $\mathrm{S} / \mathrm{N}$ ratio graph have horizontal line, it represents value of the total mean of the $\mathrm{S} / \mathrm{N}$ ratio and when graph is not horizontal, then there is a main effect present. Similarly, Different levels of the parameters affect the response variables differently.

Table 4.1 Process parameters with their values at different levels

\begin{tabular}{|c|c|c|c|c|}
\hline Parameter & Parameters Process & Level 1 & Level 2 & Level 3 \\
\hline A & Cutting Speed (rpm) & 175 & 260 & 435 \\
\hline B & Feed Rate (mm/rev) & 0.105 & 0.165 & 0.250 \\
\hline C & Depth of cut (mm) & 0.5 & 0.75 & 1.0 \\
\hline
\end{tabular}

Table 4.2 Orthogonal array $\mathrm{L}_{9}$ of Taguchi

\begin{tabular}{|c|c|c|c|}
\hline Trail No & A & B & C \\
\hline 1 & 1 & 1 & 1 \\
\hline 2 & 1 & 2 & 2 \\
\hline 3 & 1 & 3 & 3 \\
\hline 4 & 2 & 1 & 2 \\
\hline 5 & 2 & 2 & 3 \\
\hline 6 & 2 & 3 & 1 \\
\hline 7 & 3 & 1 & 3 \\
\hline 8 & 3 & 2 & 1 \\
\hline 9 & 3 & 3 & 2 \\
\hline
\end{tabular}

Taguchi Method is Conventional method for experimental design which is complex in nature and difficult to use. Taguchi method is especially suitable for scientific research use, but can also be used for industrial sectors. In order to minimize the number of experiments, a powerful tool has been designed for high quality systems by Taguchi methods. The Taguchi technique helps in data analysis and determination of optimum results. In order to evaluate optimal parameter settings, Taguchi method uses a statistical measure of performance called signal-to-noise ratio. The S/N ratio takes both the mean and the variability into account. The $\mathrm{S} / \mathrm{N}$ ratio is the ratio of the mean (Signal) to the standard deviation (Noise). The ratio depends on 
the quality characteristics of the process parameters to be optimized. The standard $\mathrm{S} / \mathrm{N}$ ratio characteristics can be divided into three categories,

- Nominal-is-Best,

- Lower-the-better and

- Higher-the-Better.

In this study, the $\mathrm{S} / \mathrm{N}$ ratio is used to measure quality characteristics and it is used to measure significant process parameters. Smaller is better $\mathrm{S} / \mathrm{N}$ ratio use in this study because is lower forces are desirable. Quality characteristic of the $\mathrm{S} / \mathrm{N}$ ratio is determined according to following equation;

$$
\text { S/N Ratio }=-10 \log \sum_{i=1}^{i=n} \frac{Y_{i}^{2}}{R}
$$

Where, $\mathrm{R}$ is the number of repetitions and $\mathrm{Yi}$ is the measured value in a row.

\subsubsection{CUTTING TOOL \& WORK SPECIFICATIONS USED}

In this research work, the workpiece is made of mild steel material as we discussed above in art.3.1. The dimensions used for the workpiece bars are of $25 \mathrm{~mm}$ diameter and $30 \mathrm{~mm}$ length. The tool is single point cutting tool which is made of High speed steel. The properties of HSS are discussed above in art.3.2. For Roughing operation, the hardened High speed steel tool bits are available in the various sizes. For this research work, the $25 \times 25 \times 150 \mathrm{~mm}$ tool bit is used as a shank of single point cutting tool. The tool signature for HSS cutting tool is taken as $7^{\circ}-10^{\circ}-9^{\circ}-8^{\circ}$ $-10^{\circ}-10^{\circ}-2 \mathrm{~mm}$.

\subsection{Experimental Observations}

For each combination of input process parameters according to orthogonal array, cutting force, feed force and radial force is determined by using dynamometer as shown in experimental setup fig.4.3.

Table 4.3 Experimental data of Feed force, Cutting force and Radial force

\begin{tabular}{|c|c|c|c|c|}
\hline $\begin{array}{c}\text { S. } \\
\text { No. }\end{array}$ & $\begin{array}{c}\text { Cutting Speed } \\
\text { (in RPM) }\end{array}$ & $\begin{array}{c}\text { Feed Rate } \\
\text { (in mm/rev) }\end{array}$ & $\begin{array}{c}\text { Depth of Cut } \\
\text { (in mm) }\end{array}$ & $\begin{array}{c}\text { Cutting Force (in Kg's) } \\
\text { (in y-direction) }\end{array}$ \\
\hline 1. & 175 & 0.105 & 0.5 & 30 \\
\hline 2. & 175 & 0.166 & 0.75 & 18 \\
\hline 3. & 175 & 0.250 & 1.0 & 54 \\
\hline 4. & 260 & 0.105 & 0.75 & 25 \\
\hline 5. & 260 & 0.166 & 1.0 & 43 \\
\hline 6. & 260 & 0.250 & 0.5 & 45 \\
\hline 7. & 435 & 0.105 & 1.0 & 19 \\
\hline 8. & 435 & 0.166 & 0.5 & 18 \\
\hline 9. & 435 & 0.250 & 0.75 & 58 \\
\hline
\end{tabular}


Dynamic Analysis and Optimization of Process Parameters in Turning Operation by Using ADAMS Software

Table 4.4 Design of experiment $\mathrm{L}_{9}$ Orthogonal Array and S/N Ratios

\begin{tabular}{|c|c|c|c|c|c|}
\hline S.No. & $\begin{array}{c}\text { Cutting } \\
\text { Speed }\end{array}$ & Feed Rate & Depth of Cut & $\begin{array}{c}\text { Cutting Force } \\
\text { (in Kg's) }\end{array}$ & $\begin{array}{c}\text { S/N Ratio for } \\
\text { Cutting Force } \\
\text { (in dB) }\end{array}$ \\
\hline 1. & 1 & 1 & 1 & 30 & -29.5424 \\
\hline 2. & 1 & 2 & 2 & 18 & -25.1055 \\
\hline 3. & 1 & 3 & 3 & 54 & -34.6479 \\
\hline 4. & 2 & 1 & 2 & 25 & -27.9588 \\
\hline 5. & 2 & 2 & 3 & 43 & -32.6694 \\
\hline 6. & 2 & 3 & 1 & 45 & -33.0643 \\
\hline 7. & 3 & 1 & 3 & 19 & -25.5751 \\
\hline 8. & 3 & 2 & 1 & 18 & -25.1055 \\
\hline 9. & 3 & 3 & 2 & 58 & -35.2686 \\
\hline
\end{tabular}

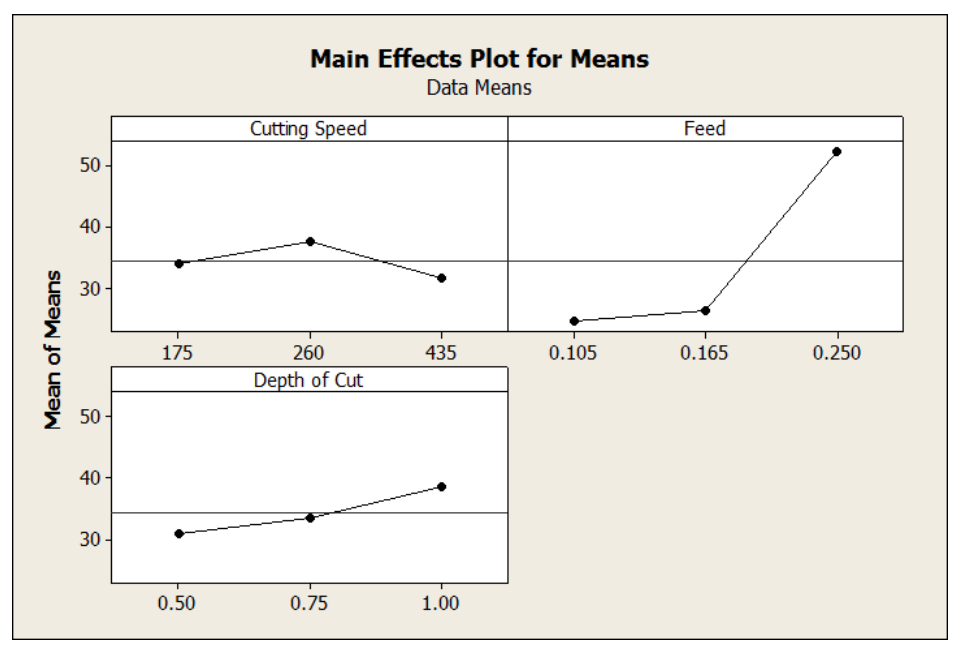

Figure 4.4 Effect of process parameter on Cutting Force

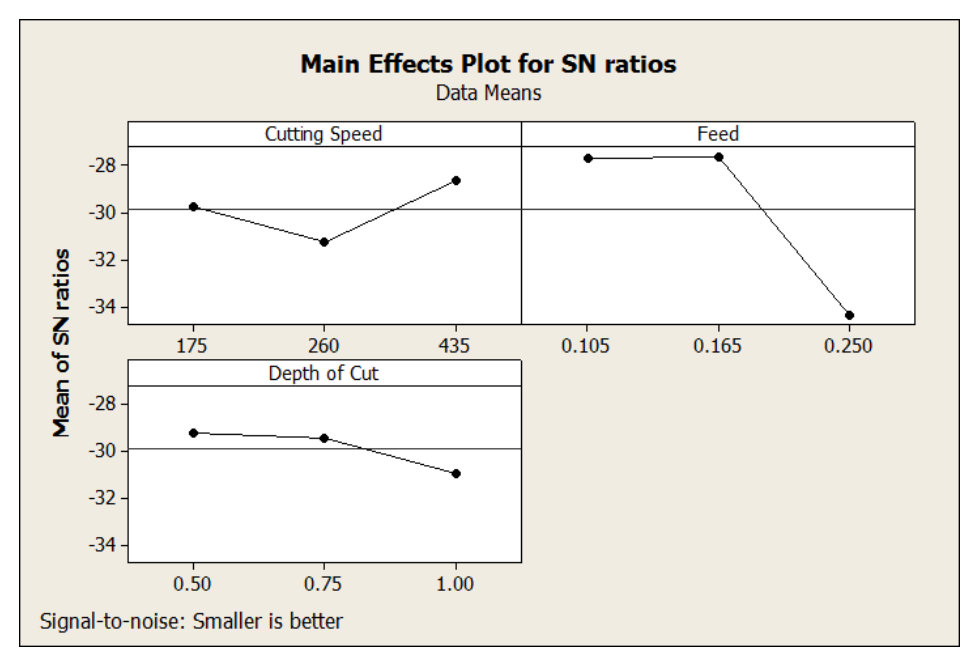

Figure 4.5 Effect of process parameters on $\mathrm{S} / \mathrm{N}$ ratios of cutting force

\subsection{Experimental Results and conclusion}

The above Fig 4.5 shows the $\mathrm{S} / \mathrm{N}$ ratio graph where the horizontal line is the value of the total mean of the $\mathrm{S} / \mathrm{N}$ ratio. Basically, the Smaller the $\mathrm{S} / \mathrm{N}$ ratio represents the better quality characteristic for the Cutting Force because our aim is to minimize the cutting force. As per the $\mathrm{S} / \mathrm{N}$ ratio analysis from graph the optimal level of 
machining performance for the forces is obtained at 260 RPM cutting speed (level 2), $0.250 \mathrm{~mm} / \mathrm{rev}$ feed rate (level 3) and $1.0 \mathrm{~mm}$ depth of cut (level 3) for Cutting force.

To ensure the above optimal setting of the input process parameters, A Confirmatory experiment is performed for the optimal input parameters obtained from the Minitab and value of cutting force is obtained by the dynamometer.

From the confirmatory experiment, we obtained value of cutting force $=\mathbf{1 7} \mathbf{~} \mathbf{g ~ o r}$ 166.77 $N$ which is the minimum value as compared to the value of cutting force in the table 4.3. So, it can be concluded that the optimal setting obtained from Taguchi design approach gives optimum process parameters for minimum cutting force on tool.

Table 4.5 Confirmatory Experimental data for minimum Cutting force

\begin{tabular}{|c|c|c|c|c|}
\hline S.No. & $\begin{array}{c}\text { Cutting Speed } \\
\text { (in RPM) }\end{array}$ & $\begin{array}{c}\text { Feed Rate } \\
\text { (in } \mathbf{~ m m} / \mathbf{r e v} \text { ) }\end{array}$ & $\begin{array}{c}\text { Depth of Cut } \\
\text { (in } \mathbf{~ m m} \text { ) }\end{array}$ & $\begin{array}{c}\text { Cutting Force } \\
\text { (in Kg's) }\end{array}$ \\
\hline 1. & 260 & 0.250 & 1.0 & 17 \\
\hline
\end{tabular}

\section{DYNAMIC ANALYSIS PROCEDURES}

The objective of this project is to reduce the both cost and time consuming of experimental method by using CAD based dynamic analysis software like ADAMs. This paper consist a software approach for dynamic analysis and optimization of process parameter in turning operation, as we discussed about turning operation in section1. ADAMs software have various tools like simulation, post processor, optimization interface etc. to dynamically analyze the turning mechanism. The turning mechanism is prepared by the various modeling tools like extrude, sweep etc. After making contact between tool and workpiece, the turning model has been simulated with the specific cutting speed and feed motion. The simulation provides the desired cutting forces on the tool. These forces are further compared and optimized with the experimental results by the help of post processor and optimization interface of ADAMs.

\subsection{Modelling of Single Point Cutting Tool}

In the way of dynamic analysis; firstly, we have to prepare a three dimensional single point cutting tool with the help of tool specifications like tool signature, shank dimensions, cutting tool material etc. In this research work; Pro-engineer wildfire 4.0, a CAD based modeling software is used for the modeling of cutting tool and the modeling has been done with the help of modeling commands like extrude, sweep, fillet etc. The model of cutting tool has shown in fig. 5.1 with specifications [at section 4.3.2] in pro-e interface. 


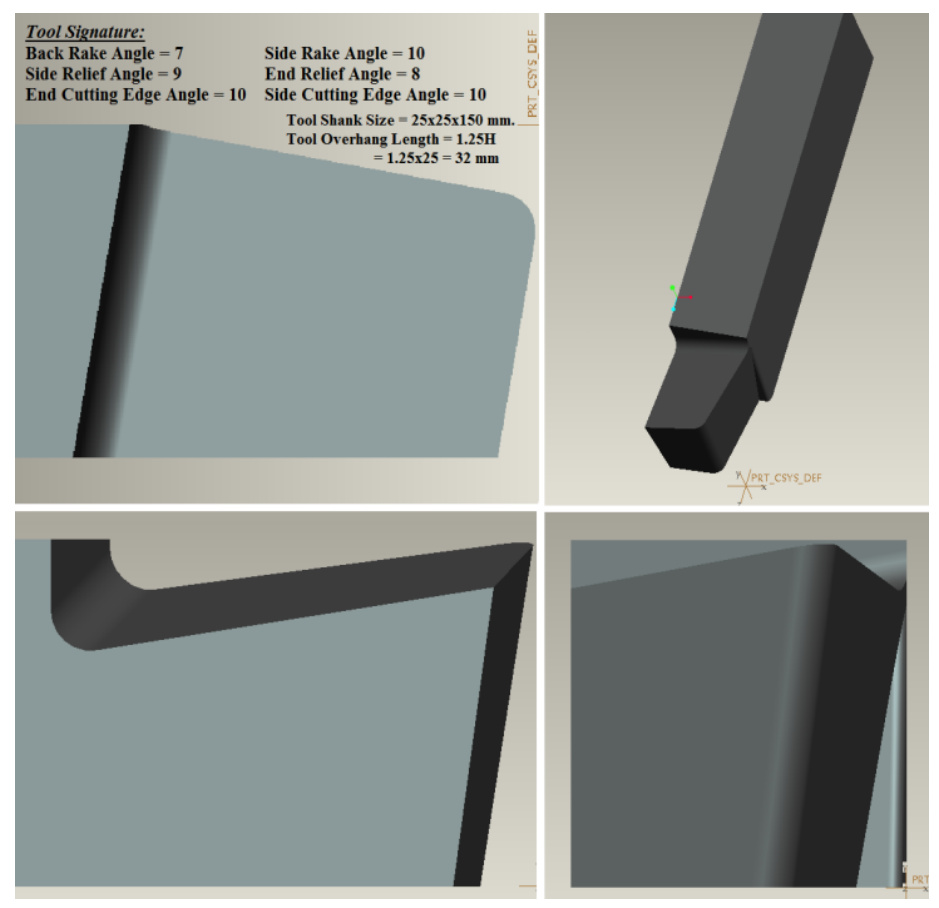

Figure 5.1 Model of Single point cutting tool in PRO-E

\subsection{Virtual Model of Turning Mechanism}

For simulation purposes a virtual model of turning mechanism was modeled by using ADAMs software. The single point cutting tool which is modeled in the PRO-E software has imported in ADAMs. Also a cylindrical workpiece model has created in the ADAMs and provided cutting speed and feed motion to workpiece and tool respectively. After this, a contact between tool and workpiece has made with various force affecting factors like Stiffness, force exponent, damping, penetration depth and co-efficient of friction etc. These factors were selected to match with the turning condition of experimental set up which was available in the workshop. This would facilitate the verification of simulation results with experimental results in the future. Figure 5.2 shows the virtual model of turning used in this work along with the constraints used.

\subsection{Dynamic Force Variation on Cutting Tool}

In this dynamic analysis, a solid to solid contact is created between tool and workpiece. The Contact load on tool when tool and workpiece are in contact does not remain constant. The load variation is mainly influenced because of following factors: (1) Varying contact stiffness, (2) Force Exponent, (3) Damping coefficient, (4) Penetration depth, (5) Contact Friction. Therefore, for simulating the dynamic conditions it is essential to correctly estimate the above factors. According to [8], afore mentioned factors are not just a material property, It is also depends on the geometry of the colliding objects and there is no handbook for choosing the value for mentioned factors. The best option is to do multiple simulations in ADAMs with different values of process parameters to determine the optimal value at which the Adams contact behavior resembles the real world contact behavior.

In this study, Adams includes a standard value for the stiffness parameter when initially setting up a contact between two objects. This value is $1.0 \mathrm{E}+005$. So, it is expected that the realistic value of stiffness would be in the range of $1.0 \mathrm{E}+003$ to 
1.0+007. The force exponent is a measurement of the non-linearity of the impact function's spring force. The recommended value for force exponent is e $>1$, because lower values will lead to discontinuities. The value of force exponent ranges from 2.2 to 15.0 for different types materials. The standard maximum damping coefficient is $0.01 \%$ of the stiffness value. The best option is to do some multiple simulations in ADAMs with different values of damping co-efficient to determine the optimal value which resembles the ADAMs contact behavior with the real contact behavior. The penetration depth in solid to solid contact should be smaller than the realistic maximum penetration depth. A reasonable value for this parameter will varies from 0.01 to $1 \mathrm{~mm}$. The coefficient of friction varies up from 0 to 1 . This coefficient is a material property; it depends on the two materials of the objects which are in contact. When choosing your own values it is remember that $\mu_{\mathrm{s}}>\mu_{\mathrm{d}}$

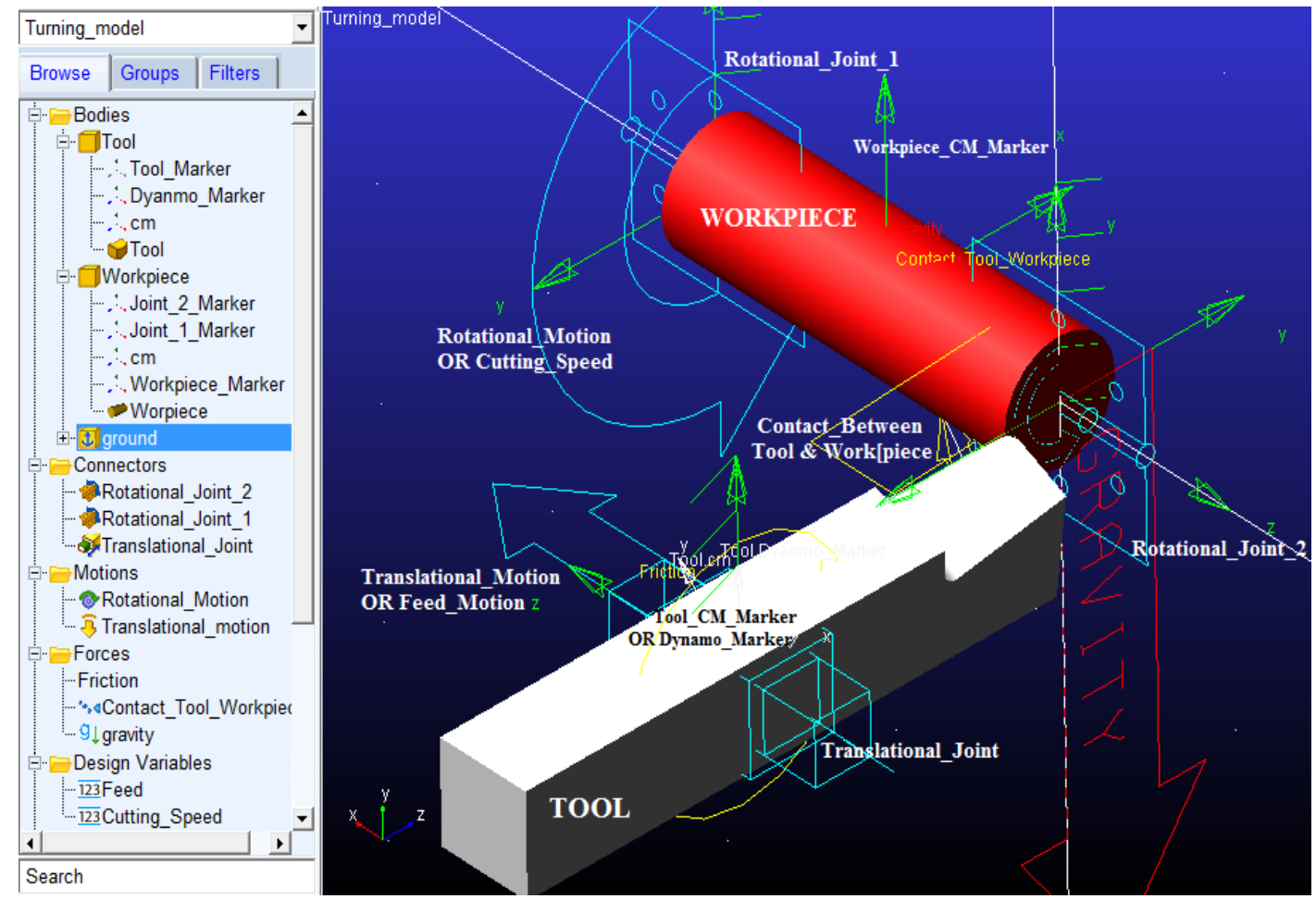

Figure 5.2 Virtual Model of Turning Mechanism in ADAMS

\subsection{Observations of Force on ADAMS}

Dynamic load variation for turning operation obtained by simulation in ADAMS is shown below in Fig 5.3a, b, c and d. It observed that the constant cutting force is closer to the experimental value of cutting force as given in table 4.3. Also, effect of process parameters, cutting speed, feed and depth of cut is clearly seen in Fig. 5.3b, c and $d$, as three waves of different amplitudes appears for e.g. Fig 5.3b shows the variation of cutting force for $0.5 \mathrm{~mm}$ depth of cut at different sets of speed and feed. The red wave is for cutting force at $S=175 \mathrm{rpm}$ and feed $=0.105 \mathrm{~mm} / \mathrm{rev}$., the blue wave is for cutting force at $S=260 \mathrm{rpm}$ and $0.250 \mathrm{~mm} / \mathrm{rev}$. and the magenta wave is for cutting force at $S=435 \mathrm{rpm}$ and feed $=0.165 \mathrm{~mm} / \mathrm{rev}$. Similarly, six more simulations are also performed for 0.75 and $1.0 \mathrm{~mm}$ depth of cut at different sets of speed and feed. In all these simulations, the values obtained from the graph is closely matching with the experimental values, so it is confirmed that turning model made in ADAMS is giving appropriate value of dynamic force. 
Dynamic Analysis and Optimization of Process Parameters in Turning Operation by Using ADAMS Software

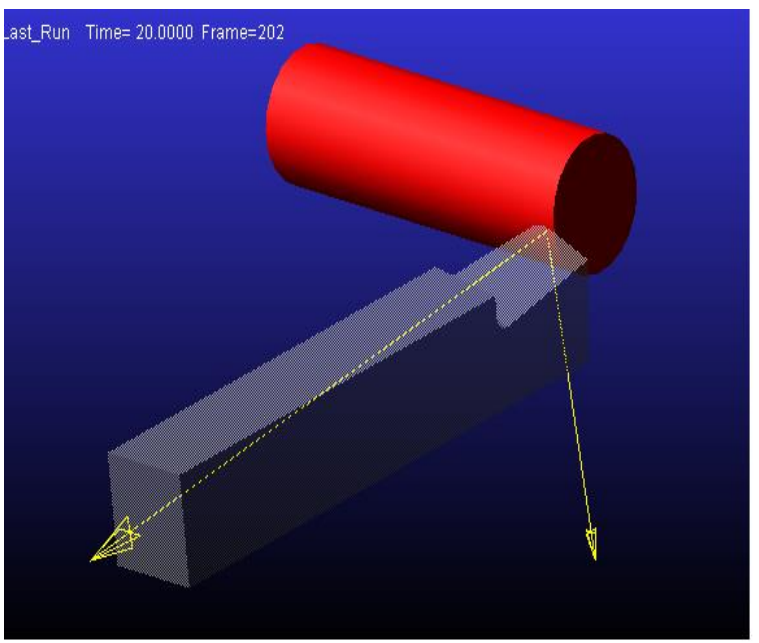

Figure 5.3a Simulation of Turning Mechanism in ADAMs

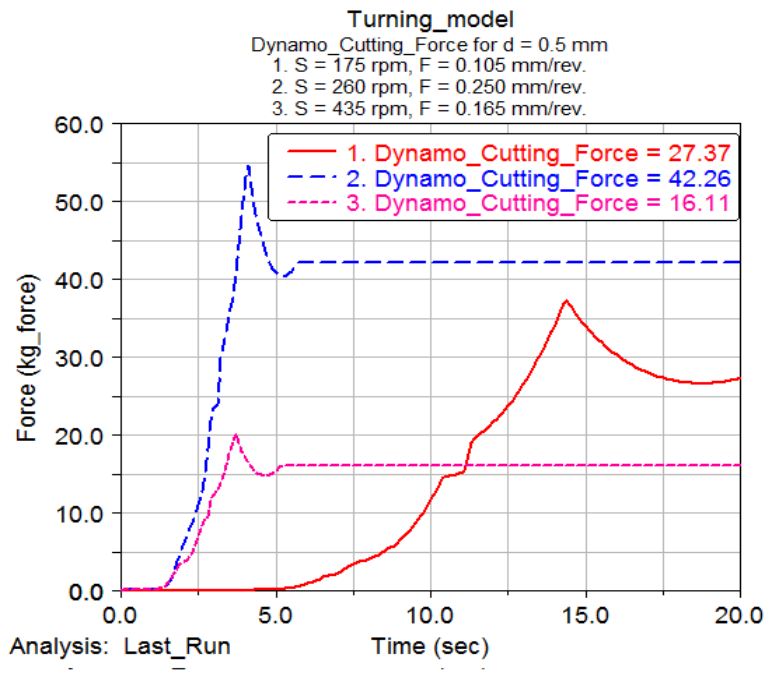

Figure 5.3b Variation of cutting force for $0.5 \mathrm{~mm}$ depth of cut

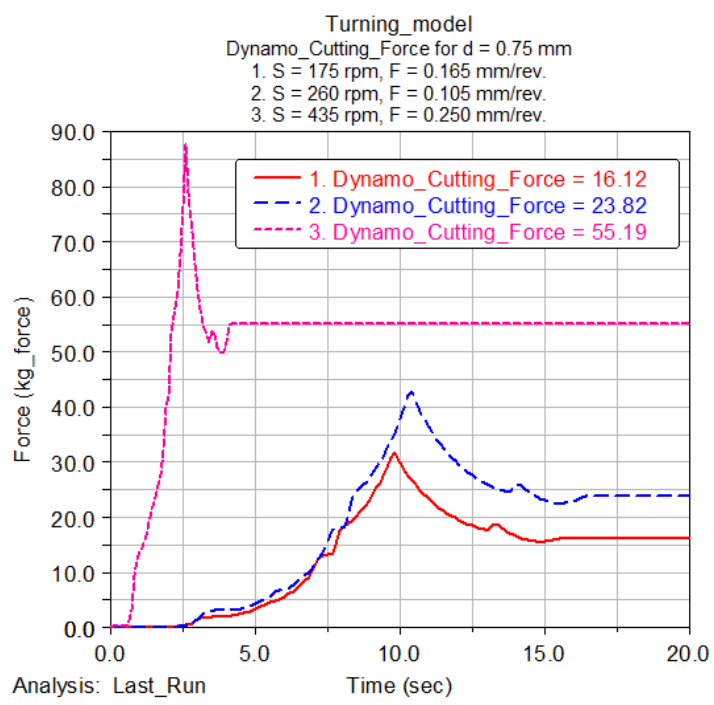

Figure 5.3c Variation of cutting force for $0.75 \mathrm{~mm}$ depth of cut 


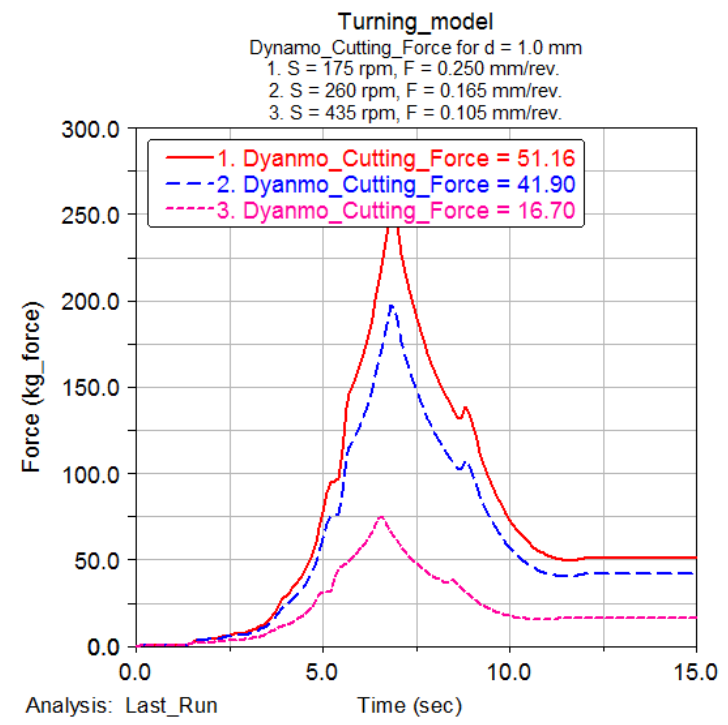

Figure 5.3d Variation of cutting force for $0.75 \mathrm{~mm}$ depth of cut

After observing the cutting forces at different process parameters, Optimization has been performed on ADAMs for different depth of cut 0.5, 0.75 and $1.0 \mathrm{~mm}$. The optimization runs between the maximum and minimum values of cutting speed and feed rates with taking minimizing the cutting force as the objective of run. At the end of optimization run, the optimal setting of cutting speed and feed rate will be shown in optimization summary report. This report gives a value of cutting force and feed at minimum cutting force for an individual depth of cuts and also plots the results in the form of graphs. For e.g. Fig 5.4a shows the optimization summary for $0.5 \mathrm{~mm}$ depth of cut and plots a graph for the results. The result of optimization run shows that the minimum cutting force of $16.114 \mathrm{Kg}$ will be obtained at Cutting Speed $=1560 \mathrm{deg} / \mathrm{sec}$ or $260 \mathrm{rpm}$ and feed $=1.0827 \mathrm{~mm} / \mathrm{sec}$ or $0.1665 \mathrm{~mm} / \mathrm{rev}$. Similarly, Fig. $5.4 \mathrm{~b}$ and Fig $5.4 \mathrm{c}$ shows the optimization summary for $0.75 \mathrm{~mm}$ and $1.0 \mathrm{~mm}$ depth of cut.

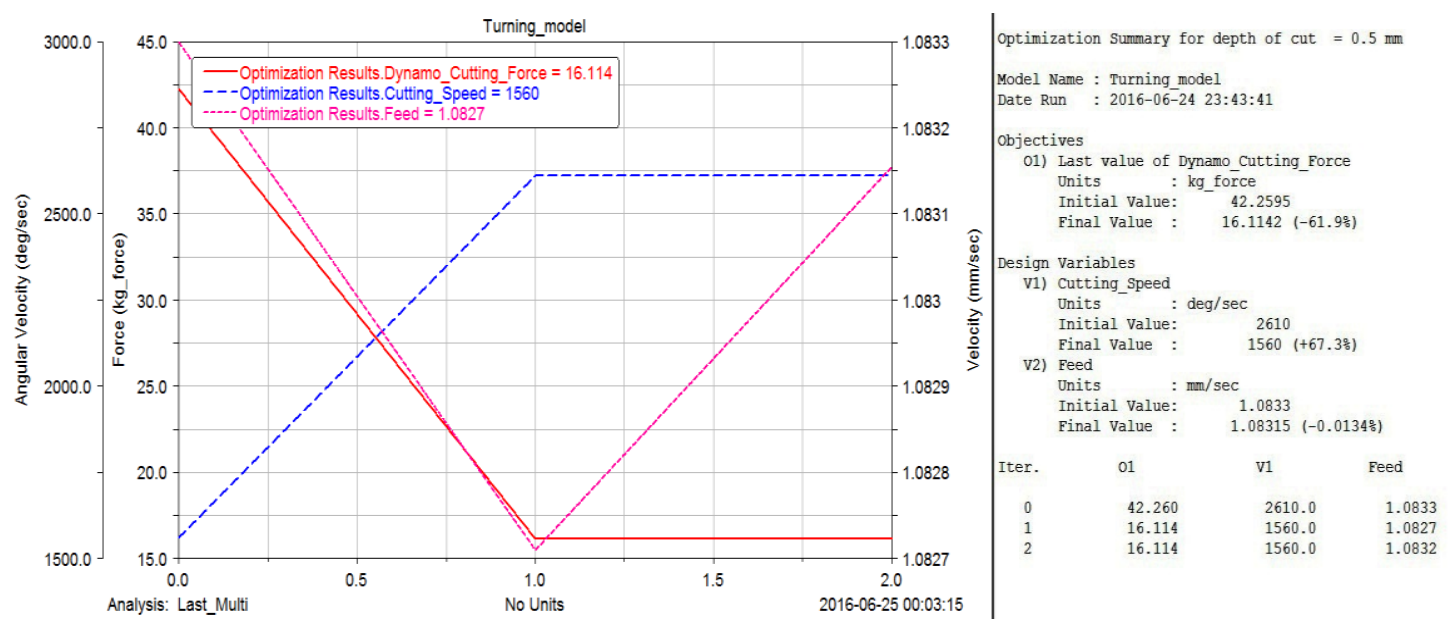

Figure 5.4a optimization summary for $0.5 \mathrm{~mm}$ depth of cut 
Dynamic Analysis and Optimization of Process Parameters in Turning Operation by Using ADAMS Software

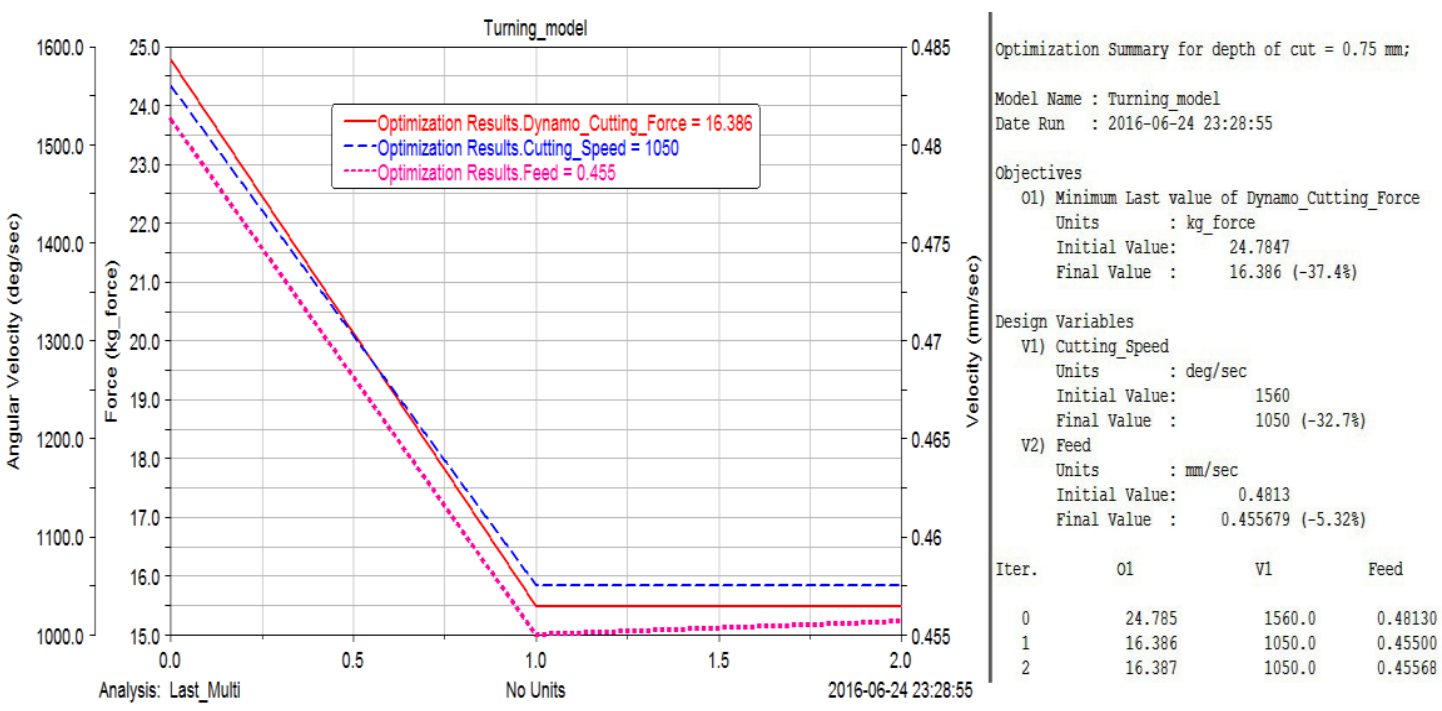

Figure 5.4b optimization summary for $0.75 \mathrm{~mm}$ depth of cut
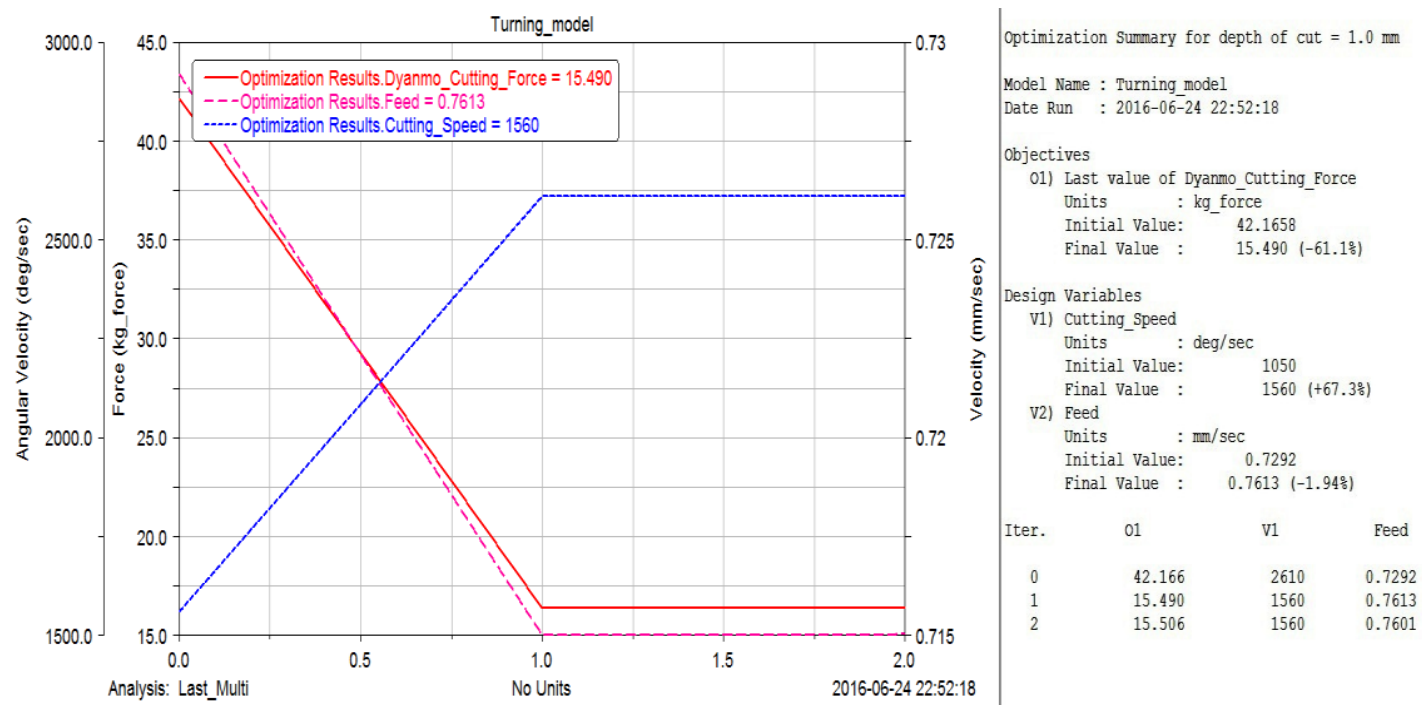

Figure 5.4c optimization summary for $1.0 \mathrm{~mm}$ depth of cut

From the above fig $5.4 \mathrm{a}, \mathrm{b}$ and $\mathrm{c}$, it is observed that the minimum cutting force $=$ $15.490 \mathrm{~kg} \mathrm{or} 151.956 \mathrm{~N}$ is obtained at $1.0 \mathrm{~mm}$ depth of cut and the optimal values of cutting speed and feed rate for $1.0 \mathrm{~mm}$ depth of cut are cutting speed $=1560 \mathrm{deg} / \mathrm{sec}$ or 260 $\mathrm{rpm}$ and feed $=0.7613 \mathrm{~mm} / \mathrm{sec}$ or $0.250 \mathrm{~mm} / \mathrm{rev}$.

\subsection{Comparision Between Experimental and Dynamic Analysis Results}

Table 5.1 shows a comparison between experimental data and analytical data of cutting forces in dynamometer and ADAMs respectively. From this comparison, it is show that ADAMs gives about $\pm 10-12 \%$ variations in the values of cutting forces and these variations are occurs due to unpredictable practical conditions like wear, jerk, vibrations, cyclic loading etc. But overall the results are same in both experimental and dynamic analysis so we can say that the ADAMs software will surely used for analyzing forces in various machining operations. Similarly, table 5.2 shows the comparison between minimum cutting forces for optimal values of process parameters. From this comparison, it is observed that ADAMs has also gives 
minimum cutting force for the same optimal values of parameters as obtained from taguchi method of optimization.

Table 5.1 Comparison between Experimental and Analytical data of Cutting force

\begin{tabular}{|c|c|c|c|c|c|}
\hline S.No. & $\begin{array}{c}\text { Cutting Speed } \\
\text { (in RPM) }\end{array}$ & $\begin{array}{c}\text { Feed Rate } \\
\text { (in } \\
\text { mm/rev) }\end{array}$ & $\begin{array}{c}\text { Depth of Cut } \\
\text { (in mm) }\end{array}$ & $\begin{array}{c}\text { Experimental Data of } \\
\text { Cutting Force in } \\
\text { Dynamometer } \\
\text { (in Kg's) } \\
\text { (in y-direction) }\end{array}$ & $\begin{array}{c}\text { Analytical Data of } \\
\text { Cutting Force } \\
\text { in ADAMs } \\
\text { (in Kg's) } \\
\text { (in x-direction) }\end{array}$ \\
\hline 1. & 175 & 0.105 & 0.5 & 30 & 27.37 \\
\hline 2. & 175 & 0.166 & 0.75 & 18 & 16.12 \\
\hline 3. & 175 & 0.250 & 1.0 & 54 & 51.16 \\
\hline 4. & 260 & 0.105 & 0.75 & 25 & 23.82 \\
\hline 5. & 260 & 0.166 & 1.0 & 43 & 41.90 \\
\hline 6. & 260 & 0.250 & 0.5 & 45 & 42.26 \\
\hline 7. & 435 & 0.105 & 1.0 & 19 & 16.70 \\
\hline 8. & 435 & 0.166 & 0.5 & 18 & 16.11 \\
\hline 9. & 435 & 0.250 & 0.75 & 58 & 55.19 \\
\hline
\end{tabular}

Table 5.2 Comparison between optimized Experimental and Analytical data of Cutting force

\begin{tabular}{|c|c|c|c|c|c|}
\hline $\begin{array}{c}\text { S.No } \\
\cdot\end{array}$ & $\begin{array}{c}\text { Cutting } \\
\text { Speed } \\
\text { (in RPM) }\end{array}$ & $\begin{array}{c}\text { Feed Rate } \\
\text { (in } \\
\text { mm/rev) }\end{array}$ & $\begin{array}{c}\text { Depth of } \\
\text { Cut } \\
\text { (in mm) }\end{array}$ & $\begin{array}{c}\text { Minimum } \\
\text { Cutting Force by } \\
\text { Taguchi Method } \\
\text { (in Kg's) } \\
\text { (in y-direction) }\end{array}$ & $\begin{array}{c}\text { Minimum } \\
\text { Cutting Force by } \\
\text { ADAMs } \\
\text { (in Kg's) } \\
\text { (in x-direction) }\end{array}$ \\
\hline 1. & 260 & 0.250 & 1.0 & 17 & 15.490 \\
\hline
\end{tabular}

\section{CONCLUSION}

The following conclusions can be drawn from this study; statistically designed experiments based on Taguchi methods are performed using L9 orthogonal arrays to analyze cutting forces as response variable. The optimal settings of various process parameters for mild steel workpiece to yield Optimal cutting force are: cutting speed $=260 \mathrm{rpm}$; feed rate $=0.250 \mathrm{~mm} / \mathrm{rev}$; depth of cut $=1.0 \mathrm{~mm}$ predicted by Taguchi method. The optimized machining parameter from the present study can be used for machining different metals and composites. In this paper work, an additional attempt has been made to present the simulation of dynamic force variation for Turning Operation under different process parameters. It has been shown that ADAMS - View can be used for dynamics simulation of turning operations using virtual model of turning mechanism. Initially, virtual model of the turning mechanism was made in CAD software and its cutting force variation was obtained. This dynamic force magnitude was confirmed by experimental calculations. The Optimization of process parameters for minimum cutting force has also done through the ADAMs software and it is found from the observations that the optimal settings of various parameters are same as found by Taguchi method. The comparisons between experimental and dynamic analysis shows some variations about $\pm 10-12 \%$ in the values of cutting forces but we can say that the variations are due to unpredictable practical conditions like wear, jerk, vibrations, cyclic loading etc. But since, the results are same in both 
experimental and dynamic analysis so we can say that the ADAMs software will surely used for analyzing forces in various machining operations and this will lead to elimination of the expensive experimental setup, time consuming procedures and complex numerical calculations.

\section{REFERENCES}

[1] W.H. Yang, Y.S. Tarng, "Design optimization of cutting parameters for turning operations based on the Taguchi method", Journal of Materials Processing Technology, 1998, Volume 84, Issues 1-3, pp. 122-129

[2] G.M.Sayeed Ahmeda, S. Sibghatullah Hussaini Quadri and Md Sadiq Mohiuddin; Optimization of Feed and Radial Force in Turning Process by using Taguchi Design Approach, 2 (2015) 3277 - 3285.

[3] Atul B. Andhare and Manish Kumar Verma (2015); Modeling and Dynamic Force Simulation for Detection of Profile Error in Spur Gear Pair, 23, DOI 10.1007/978-3-319-09918-7_97.

[4] Kamble N, Saha SK (2007); developing a virtual prototype of a rack and pinion steering system, International Journal of Vehicle Systems Modelling and Testing2 (2007):61-79.

[5] Kadir Gok (2015); Development of three-dimensional finite element model to calculate the turning processing parameters in turning operations, 75 (2015) 57-68.

[6] MSC Inc., MSC ADAMS reference manual.

[7] Adams Tutorial Kit for Mechanical Engineering Courses; a Textbook for Design of Machinery by Robert L. Norton.

[8] Jochem Giesbers (2012); Contact Mechanics in MSC ADAMs, A technical evaluation of the contact models in Multibody dynamics software MSC Adams.

[9] G. R. Nagpal (2009); Machine Tool Engineering, Khanna Publishers.

[10] P. N. Rao (2011); Manufacturing Technology, Metal Cutting and Machine Tools Volume 2, Second Edition, McGraw Hill Publishers.

[11] Hemant Jaina, Jaya Tripathi, Ravindra Bharilya, Sanjay Jain and Avinash Kumar (2015); Optimization and evaluation of machining parameters for turning operation of Inconel-625, 2 (2015) 2306 - 2313.

[12] Khaider Bouacha, Mohamed Athmane Yallese, Samir Khamel and Salim Belhadi (2014); Analysis and optimization of hard turning operation using cubic boron nitride tool, 45 (2014) 160-178.

[13] Dr R. P. Sharma and Chikesh Ranjan, Modeling and Simulation of FourBar Planar Mechanisms Using ADAMS. International Journal of Mechanical Engineering and Technology 4(2), 2013, pp. 429-435.

[14] Ganesan.H, Mohankumar. G, Study on Optimization of Machining Parameters in Turning Process Using Evolutionary Algorithm with Experimental Verification. International Journal of Mechanical Engineering and Technology 2(1), 2011, pp. 10-21.

[15] Howard I, Jia S, Wang J (2001); the dynamic modeling of spur gear in mesh including friction and a crack. Mech Syst Signal Process; 15(5):831853. 